\title{
XB130 deficiency enhances lipopolysaccharide-induced septic response and acute lung injury
}

\author{
Hiroaki Toba ${ }^{1}$, Tereza Tomankova ${ }^{1}$, Yingchun Wang ${ }^{1}, \mathrm{Xiaohui}_{\mathrm{Bai}}{ }^{1}, \mathrm{Hae}^{\mathrm{Ra}} \mathrm{Cho}^{1}$, \\ Zhehong Guan' ${ }^{1}$, Oyedele A. Adeyi ${ }^{2}$, Feng Tian ${ }^{1}$, Shaf Keshavjee ${ }^{1,3,4}$, Mingyao Liu ${ }^{1,3,4}$ \\ ${ }^{1}$ Latner Thoracic Surgery Research Laboratories, Toronto General Hospital Research Institute, Universal Health Network, \\ University of Toronto, Toronto, Ontario, Canada \\ ${ }^{2}$ Department of Laboratory Medicine and Pathobiology, University of Toronto, Toronto, Ontario, Canada \\ ${ }^{3}$ Department of Surgery, University of Toronto, Toronto, Ontario, Canada \\ ${ }^{4}$ Institute of Medical Science, Faculty of Medicine, University of Toronto, Toronto, Ontario, Canada \\ Correspondence to: Mingyao Liu, e-mail: mingyao.liu@utoronto.ca
}

Keywords: cell death, cell proliferation, inflammatory response, septic response, transgenic mouse

Received: August 31, $2015 \quad$ Accepted: March 08, 2016

Published: March 23, 2016

\section{ABSTRACT}

XB130 is a novel oncoprotein that promotes cancer cell survival, proliferation and migration. Its physiological function in vivo is largely unknown. The objective of this study was to determine the role of XB130 in lipopolysaccharide (LPS)-induced septic responses and acute lung injury. LPS was intraperitoneally administrated to $X$ X130 knockout (KO) and wild type (WT) mice. There was a significant weight loss in KO mice at Day 2 and significantly higher disease scores during the 7 days of observation. The levels of tumor necrosis factor-alpha, monocyte chemoattractant protein-1, interleukin-6 and interleukin-10 in the serum were significantly higher in $\mathrm{KO}$ mice at Day 2. In KO mice there were a significantly higher lung injury score, higher wet/dry lung weight ratio, more apoptotic cells and less proliferative cells in the lung. Macrophage infiltration was significantly elevated in the lung of KO mice. There was significantly increased number of $\mathrm{p}-\mathrm{GSK}-3 \beta$ positive cells in KO mice, which were mainly neutrophils and macrophages. XB130 is expressed in alveolar type I and type II cells in the lung. The expression in these cells was significantly reduced after LPS challenge. XB130 deficiency delayed the recovery from systemic septic responses, and the presence of XB130 in the alveolar epithelial cells may provide protective mechanisms by reducing cell death and promoting cell proliferation, and reducing pulmonary permeability.

\section{INTRODUCTION}

$\mathrm{XB130}$ is a novel adaptor protein for signal transduction $[1,2]$. Due to its high molecular similarity with actin filament associated protein (AFAP), XB130 is also known as actin filament associated protein 1-like 2 (AFAP1L2) [3, 4]. XB130 regulates cell proliferation and cell cycle progression, prevents cell death, and promotes cell migration, through its interaction with $\mathrm{Src}$ protein tyrosine kinase, and its binding with $\mathrm{p} 85 \alpha$, the regulatory subunit of PI3K, subsequently activating the PI3K/Akt pathway [1, 3-9].

$\mathrm{XB130}$ was found in colorectal cancer cells as a Src family kinase target [10], and then found as a target of
RET/PTC oncogenic kinase in thyroid cancer cells [6]. $\mathrm{XB} 130$ protein expression was not associated with the postoperative prognosis of patients with hepatocellular carcinoma [11]. By contrary, XB130 expression was an independent prognostic factor in human esophageal squamous cell carcinoma [12]. In gastric cancer, reduced $\mathrm{XB} 130$ protein expression is a prognostic biomarker for shorter survival and a higher recurrence rate [13]. On the other hand, in human ductal breast cancer, XB130 was present in the cytoplasm of malignant cells, but not in the normal breast cells, and positive XB130 expression was an independent risk factor for overall survival and recurrence free survival [14]. XB130, thus, may play different role in tumorigenesis depending upon the types of cancers. 
Since most of cell biology studies on XB130 were conducted in cancer cells, the physiological function of $\mathrm{XB130}$ is largely unknown. Recently, there is a report that translocation of XB130 from cytoplasm to microfilamentous structure is involved in NNK (a cigarette smoking component) induced migration of normal human bronchial epithelial cells [8]. Moreover, the interaction between XB130 and another adaptor protein, Tks5, mediates EGF and serum-induced proliferation and survival of human bronchial epithelial cells [15]. To determine the physiological function and tumorigenesis of XB130 in vivo, XB130 knockout (KO) mice have been generated. XB130 deficiency could slow down the differentiation of proliferating basal cells to ciliated epithelial cells during the repair process in trachea [16]. XB130 also promotes bronchioalveolar stem cell and Club cell proliferation in small airway repair and regeneration [17]. The objective of the present study is to determine the role of XB130 in septic response and acute lung injury.

Acute lung injury (ALI) and its severe form, acute respiratory distress syndrome (ARDS), are critical and leading cause of mortality in the Intensive Care Units. In United States, there were approximately 190,000 patients of ALI/ARDS each year with approximately $40 \%$ mortality [18]. ALI/ARDS can be caused by intrapulmonary insults (such as infection, acid aspiration, ventilator-induced lung injury, ischemia-reperfusion, and etc.), as well as by extrapulmonary insults (such as sepsis, hemorrhagic shock, trauma, burn, and etc.) [19]. Lipopolysaccharide (LPS) binds to Toll-like receptor 4, and induces the production of various pro-inflammatory cytokines and development of ALI [20].

Multiple intracellular signal transduction pathways mediates ALI/ARDS [21]. For example, PI3K/Akt, mitogen-activated protein kinase, c-Jun N-terminal protein kinase and p38 activation are involved in the overproduction of reactive oxygen species, inflammatory response, cell death and alveolar epithelial cell injury [22]. Since XB130 is an upstream signal of Src, and PI3K/Akt, we used $X b 130 \mathrm{KO}$ and wild type (WT) mice to determine the role of XB130 in LPS-induced septic response and ALI.

\section{RESULTS}

\section{Xb130 KO mice were more susceptible to LPS-induced septic responses}

To examine the role of XB130 in LPS-induced systemic septic response, WT and $X b 130 \mathrm{KO}$ mice were challenged with $25 \mathrm{mg} / \mathrm{kg}$ LPS. Seven days' survival of Xb130 KO mice (60\%) was lower than WT mice $(90 \%)$, even though it did not reach statistical significance $(p=0.11)$ (Figure 1A). Xb130 KO mice revealed a significant weight loss at Day 2 (Figure 1B). Composite disease scores, a marker of the severity of systemic sepsis, were significantly higher in Xb130 KO mice during the 7 days of observation period (Figure 1C).

LPS stimulation induced rapid significant increase in serum levels of monocyte chemoattractant protein-1 (MCP-1), interleukin-6 (IL-6), tumor necrosis factoralpha (TNF- $\alpha$ ), and IL-10 in both Xb130 KO and WT mice (Figure $2 \mathrm{~A}$ and $2 \mathrm{~B}$ ). It also rapidly and significantly increased serum levels of IL-1ß, IL-12p70, IL-13, IL-17 and IFN $\gamma$ (Table 1). At Day 2 after LPS treatment, most of these cytokines returned to basal levels in WT mice, but the levels of MCP-1, TNF- $\alpha$, IL-6 and IL-10 in Xb130 KO mice were significantly higher compared to those in WT mice (Figure 2A and 2B).

\section{XB130 deficiency led to more severe lung injury}

Acute lung injury is one of the severe complications of sepsis [19]. To determine the role of XB130 in LPSinduced lung injury, a separate group of animals was given LPS, or PBS as a negative control. Again, at Day 2 after LPS treatment, Xb130 KO mice revealed a significant weight loss (Figure 3A). Significantly higher composite disease scores were found both at Day 1 and Day 2 after LPS challenge in $\mathrm{KO}$ mice (Figure $3 \mathrm{~B}$ ). $\mathrm{H} \&$ E staining of lung tissue sections revealed more severe lung injury in Xb130 KO mice at Day 2 (Figure 3C), with significantly higher lung injury score (Figure 3D) and wet/dry lung weight ratio (Figure $3 \mathrm{E}$ ), indicating severe lung injury and pulmonary edema.

The spleens harvested after 6 hours showed normal pulp and peri-arteriolar lymphoid cells in mice that received PBS. The spleens from KO and WT mice that received LPS were congested characterized by expanded red pulp relative to the peri-arteriolar lymphoid cells. After 48 hours the spleens of LPS-treated mice in both the KO and WT group showed less congestion and appear similar to the 6 hour PBS spleens. At Day 2, the glomeruli and tubules of the renal cortices show preserved architecture. The liver parenchyma was also intact with normal portal tracts and lobular architectures. No significant differences were noted between WT and KO groups in LPS-treated animals in the spleen, kidney and liver (Supplementary Figure S1), suggesting the differences observed in the lung are organ-specific.

At Day 2 after LPS treatment, more numbers of apoptotic (TUNEL+) cells in the lung were observed in $\mathrm{Xb130} \mathrm{KO}$ mice compared to WT mice (Figure 4A and $4 \mathrm{C}$ ). By contrast, immunohistochemistry staining for Ki-67, a marker for proliferative cells, was significantly

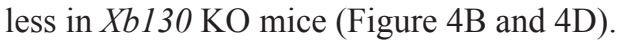

At Day 2 after LPS treatment, the number of neutrophils (Ly-6B.2+) in the lung tissue was higher in Xb130 KO mice (Figure 5A), but did not reach statistical significance (Figure 5C). On the other hand, the number 
A

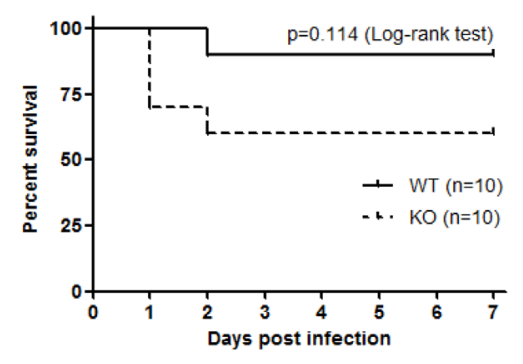

B

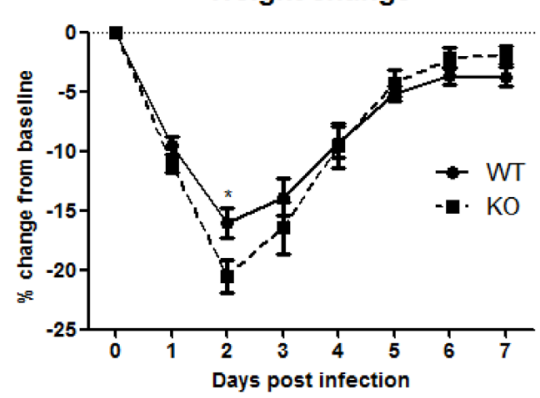

$\mathrm{C}$

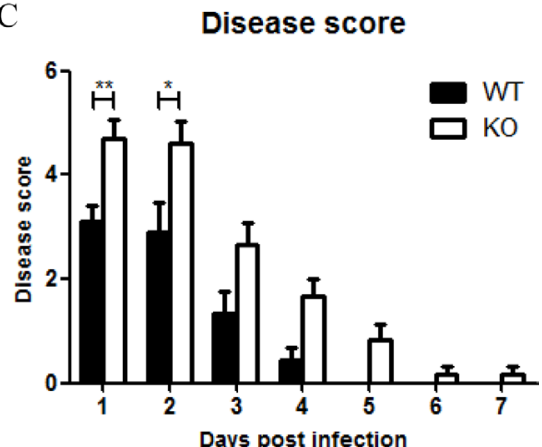

Figure 1: XB130 deficiency increased LPS-induced septic response in mice. (A) Kaplan-Meier survival curves of WT mice and $X b 130 \mathrm{KO}$ mice after LPS treatment $(25 \mathrm{mg} / \mathrm{kg})$. Difference in mortality was evaluated according to log-rank test $(p=0.114)$. Weight loss (B) and composite disease score (C) were recorded on different days. ${ }^{*} p<0.05,{ }^{* *} p<0.01$, WT $=$ Wild type, $\mathrm{KO}=X b 130$ knockout.

A
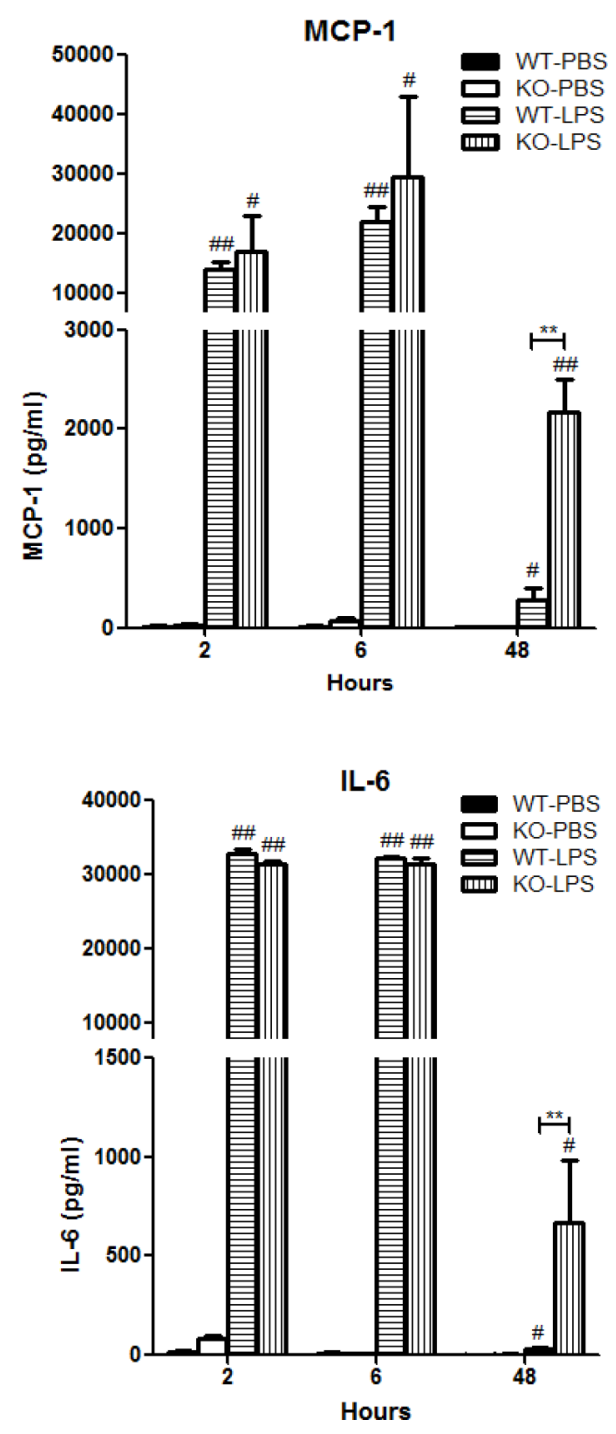

B
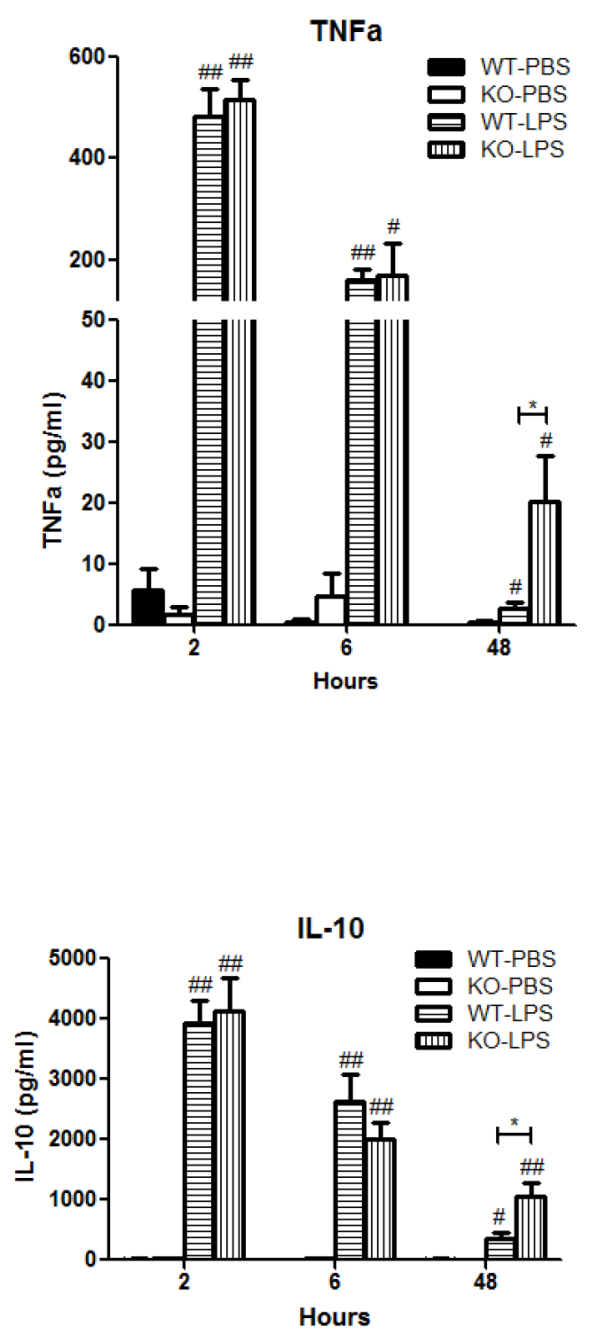

Figure 2: XB130 deficiency enhanced LPS-induced cytokine production. (A and B) Cytokine/chemokine levels in serum were measured at 2, 6 and 48 hours after LPS treatment. ${ }^{*} p<0.05$ and ${ }^{* *} p<0.01$ (WT vs. KO), ${ }^{*} p<0.05$ and ${ }^{* \#} p<0.01$ (PBS groups vs. LPS groups), $\mathrm{WT}=$ Wild type, $\mathrm{KO}=X b 130$ knockout. 
Table 1: Cytokine/chemokine levels in serum

\begin{tabular}{|c|c|c|c|c|c|c|c|c|c|c|c|c|}
\hline & \multicolumn{4}{|l|}{$2 \mathrm{hr}$ (Serum) } & \multicolumn{4}{|l|}{$6 \mathrm{hr}$ (Serum) } & \multicolumn{4}{|l|}{48 hr (Serum) } \\
\hline & WT-PBS & KO-PBS & WT-LPS & KO-LPS & WT-PBS & KO-PBS & WT-LPS & KO-LPS & WT-PBS & KO-PBS & WT-LPS & KO-LPS \\
\hline IL-1 $\alpha$ & $243.19 \pm 85.69$ & $170.94 \pm 46.50$ & $224.8 \pm 29.5$ & $154.1 \pm 18.7$ & $324.3 \pm 135.2$ & $184.5 \pm 52.1$ & $200.64 \pm 39.61$ & $206.69 \pm 32.31$ & $147.4 \pm 46.6$ & $275.7 \pm 119.9$ & $67.98 \pm 24.60$ & $103.93 \pm 22.37$ \\
\hline IL-1 $1 \beta$ & $6.55 \pm 4.55$ & 0 & $122.3 \pm 15.3^{\#}$ & $106.7 \pm 7.46$ & 0 & $33.25 \pm 33.25$ & $152.96 \pm 48.08$ & $146.00 \pm 43.15$ & $0.73 \pm 0.73$ & 0 & $1.78 \pm 0.79$ & $6.96 \pm 4.55$ \\
\hline IL-2 & $5.09 \pm 4.25$ & 0 & $5.36 \pm 3.59$ & 0 & 0 & 0 & $0.57 \pm 0.57$ & 0 & 0 & 0 & 0 & 0 \\
\hline IL-4 & $4.67 \pm 2.08$ & $1.02 \pm 0.15$ & $8.70 \pm 5.04$ & $1.08 \pm 0.16$ & $0.68 \pm 0.13$ & $3.32 \pm 2.74$ & $1.87 \pm 0.70$ & $0.64 \pm 0.07$ & $0.92 \pm 0.13$ & $0.76 \pm 0.26$ & $1.26 \pm 0.31$ & $2.00 \pm 1.08$ \\
\hline $\begin{array}{l}\text { IL- } \\
12 \text { p70 }\end{array}$ & $20.23 \pm 4.64$ & $10.11 \pm 3.17$ & $147.7 \pm 60.6^{\# \#}$ & $53.7 \pm 9.7^{\text {H\# }}$ & $5.83 \pm 5.83$ & $37.87 \pm 36.98$ & $69.84 \pm 18.74^{\#}$ & $24.64 \pm 7.30$ & $16.46 \pm 8.78$ & $24.94 \pm 24.94$ & $1.95 \pm 1.95$ & $16.88 \pm 13.28$ \\
\hline IL-13 & $30.77 \pm 14.48$ & $0.82 \pm 0.82$ & $96.93 \pm 76.27$ & $22.7 \pm 9.6^{\#}$ & $18.98 \pm 6.99$ & $17.22 \pm 7.03$ & $1.86 \pm 1.86$ & $7.13 \pm 4.58$ & $31.22 \pm 9.32$ & $9.43 \pm 5.48$ & $16.13 \pm 8.19$ & $8.72 \pm 6.30$ \\
\hline IL-17 & $10.32 \pm 4.89$ & $4.26 \pm 0.78$ & $32.9 \pm 14.9^{\circ *}$ & $8.1 \pm 0.75^{\# \#}$ & $3.22 \pm 0.82$ & $3.77 \pm 1.21$ & $898.16 \pm 370.78^{\# \prime}$ & $342.33 \pm 170.86^{\sharp}$ & $2.92 \pm 0.24$ & $2.68 \pm 1.19$ & $3.01 \pm 0.42$ & $5.20 \pm 0.85$ \\
\hline IFN $\gamma$ & $7.77 \pm 6.03$ & $0.44 \pm 0.44$ & $18.19 \pm 8.54$ & $6.9 \pm 3.01^{*}$ & 0 & 0 & $1021.71 \pm 454.44$ & $1174.40 \pm 608.20$ & $1.11 \pm 1.10$ & 0 & $1.61 \pm 1.33$ & $12.95 \pm 12.71$ \\
\hline
\end{tabular}

$* * p<0.01$ (WT vs. KO)

${ }^{\#} p<0.05,{ }^{\# \#} p<0.01$ (PBS vs. LPS)

of macrophages $(\mathrm{F} 4 / 80+)$ in the lung was significantly elevated in $\mathrm{Xb130} \mathrm{KO}$ mice compared to WT mice (Figure 5B and 5D).

In $X b 130$ KO mice, more $p$-GSK-3 $\beta$ positive cells were observed in the alveolar spaces (Figure 6A and $6 \mathrm{~B})$. To determine in which cell types p-GSK-3 $\beta$ positive staining was evident, co-IF staining for $p$-GSK- $3 \beta$ together with markers for either macrophages (F4/8), neutrophils (Ly-6B.2) or type II pneumocytes (SFTPC) was performed. Figure $6 \mathrm{C}-6 \mathrm{E}$ revealed that both macrophages and neutrophils, but not alveolar type II cells, were costained with p-GSK-3 $\beta$.

\section{Xb130 expression was reduced in the lung after LPS administration}

$\mathrm{XB130}$ is known to express in epithelial cells of various human organs $[3,9,16]$. However, the expression of XB130 has not been assessed in mouse lung yet. To detect the expression and location of XB130 in alveoli, co-IF staining for either Podoplanin (PDPN, a marker for alveolar type I epithelial cell), or Surfactant protein C (SFTPC, a marker for alveolar type II epithelial cell), together with XB130 was performed. In WT mice, $\mathrm{XB} 130$ was expressed in the cytoplasm of both type I and type II alveolar epithelial cells (Figure 7). As expected, no expression of XB130 was found in $\mathrm{Xb130} \mathrm{KO}$ mice (data not shown). XB130 staining was also observed in alveolar epithelial cells in the human lung (data not shown).

The Xb130 mRNA levels were significantly lower in the lung tissue of WT mice 2 days after LPS administration than that in the PBS control group (Figure 8A). XB130 was stained in alveolar epithelial cells in the PBS control group, but very low in LPS treated group (Figure 8B).

\section{DISCUSSION}

In this study, we showed that XB130 might play protective roles in LPS-induced systemic septic response and acute lung injury.

Endotoxin-induced septic shock is the most common cause of morbidity and mortality in intensive care units. To determine if XB130 plays a role in systemic septic response, we challenged animals with LPS intraperitoneally. We observed significant differences between $X b 130 \mathrm{KO}$ and WT mice, in terms of body weight loss and composite disease score after LPS treatment. Moreover, the serum levels of several cytokines at Day 2 of LPS treatment were significantly higher in $X b 130 \mathrm{KO}$ mice. MCP-1 is a CC chemokine for the recruitment of monocytes and other inflammatory cells to the sites of tissue injury and infection $[23,24]$. The pro-inflammatory cytokines (TNF- $\alpha$ and IL-6) can activate neutrophils, which adhere to the affected capillary endothelium and migrate into air spaces, leading to severe lung injury $[25,26]$. IL-10 is an anti-inflammatory cytokine and plays protective roles in controlling immunopathology during ALI $[27,28]$. The expression of IL-10 can be rapidly induced by pro-inflammatory cytokines such as TNF- $\alpha$ $[27,28]$. In this study, the levels of these cytokines in serum increased at 2 and 6 hours after LPS treatment in both groups, and then decreased in WT mice at Day 2, but

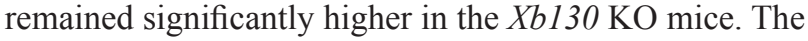
XB130 deficiency may not affect LPS challenge-induced rapid systemic inflammatory response, but may delay the recovery. At Day 2, the histology of spleen, kidney and liver appeared relatively normal, which may be due to the recovery of these critical organs from LPS challenge. The gene expression of XB130 is relatively higher in the spleen [6], which is important for immunological response. However, we did not see morphological differences between KO and WT in the spleen, kidney and liver. Therefore, why serum cytokine levels in KO mice remaining high should be further studied.

Acute lung injury is one of the most common and severe complications in septic shock [19]. In the present study, severe lung injury with more apoptotic cells, and higher W/D weight ratio and less cell proliferation were observed in Xb130 KO mice at Day 2 after LPS treatment. Cell death and inflammation may contribute to increased vascular permeability and tissue damage [29, 30]. Xb130, as an upstream regulator of PI3K/Akt pathway, specifically binds $\mathrm{p} 85 \alpha$ subunit of PI3K and leads to its activation [6]. Knocking down Xb130 with siRNA in thyroid or lung cancer cells reduced cell survival, increased susceptibilities of cells to extrinsic and intrinsic signalinduced cell death, which was associated with increased 
cleavage of caspase- 8 and caspase-9. Down-regulation of XB130 also reduced cell proliferation and cell cycle progression, together with reduced phosphorylation of p21, p27, GSK-3 $\beta$ and FOXO3 $\alpha[3,7,31]$. XB130 is also required for $\mathrm{CAMP}$-induced amplification of IGF related mitogenicity in thyroid cells [9]. We did not specify the cell types that undergoing apoptosis or proliferation,

A

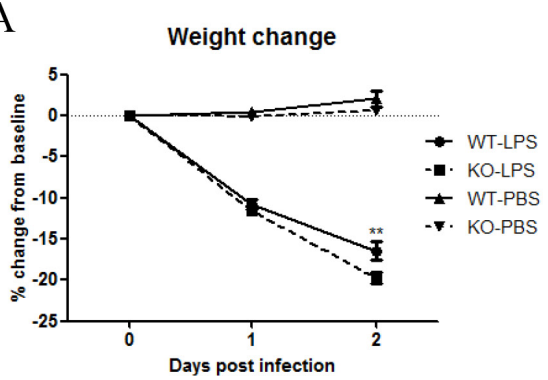

$\mathrm{C}$
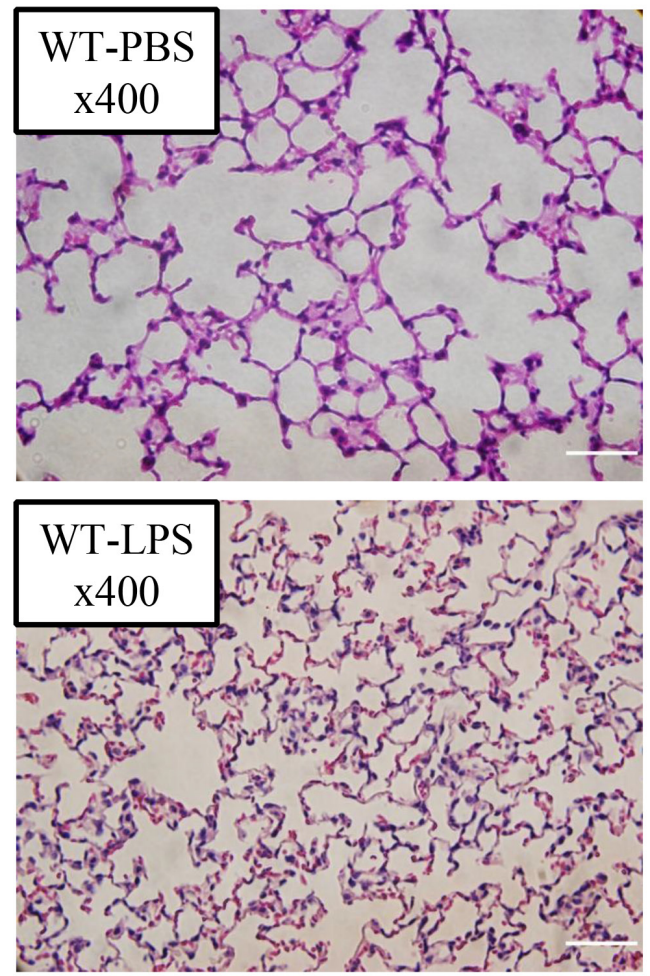

D

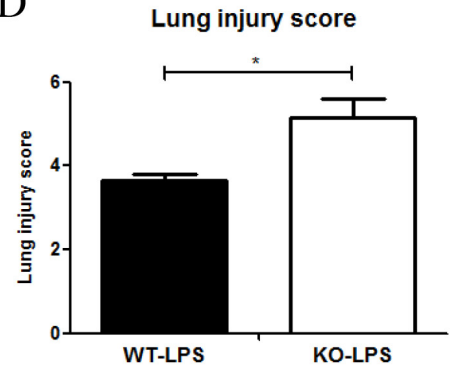

however, we did show expression of XB130 in the alveolar epithelial cells. Thus, we would like to propose that the lack of XB130 in lung epithelial cells may contribute to apoptotic cell death in the lung after LPS stimulation, and subsequently increase the pulmonary permeability and edema. The reduced cell proliferation may explain the delayed repair of lung epithelium.

B
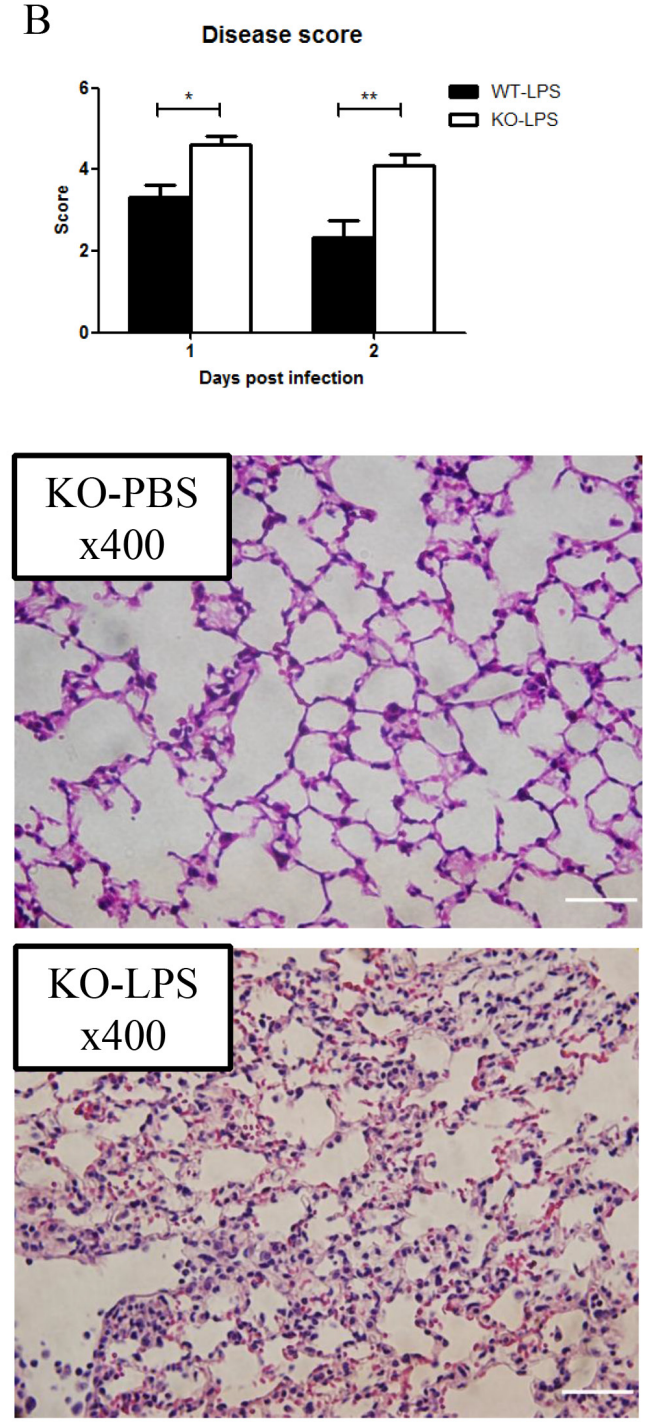

$\mathrm{E}$

WID ratio

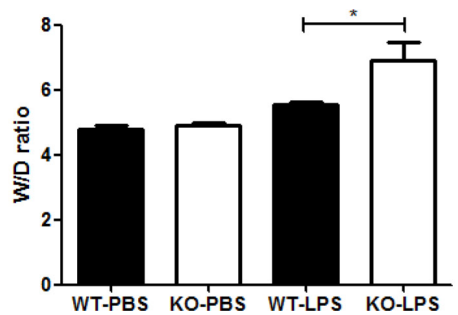

Figure 3: XB130 deficiency enhanced LPS-induced lung injury. Weight loss (A) and composite disease score (B) were recorded for 2 days after LPS treatment. (C) Hematoxylin and Eosin staining showed severe lung injury in $X b 130$ KO mice at Day 2 after LPS challenge. Scale Bars $=50 \mu \mathrm{m}$. Lung injury score (D) and W/D weight ratio (E) were significantly higher in $X b 130 \mathrm{KO}$ mice. ${ }^{*} p<0.05$, $* * p<0.01, \mathrm{WT}=$ Wild type, $\mathrm{KO}=X b 130$ knockout, $\mathrm{W} / \mathrm{D}=$ wet $/$ dry. 
To determine whether the lack of XB130 expression affects PI3K/Akt pathway, we performed IHC staining for phosphorylated $\mathrm{p} 85 \alpha$, Akt and GSK-3 $\beta$ on lung tissues. The staining of these proteins was very weak on the alveolar wall in both WT and KO animals (data not shown). After LPS treatment, Xb130 mRNA level was significantly reduced in the lung of WT mice, and the staining for XB130 was also extremely weak in alveolar cells. LPS and TNF- $\alpha$ treatment reduced XB130

A
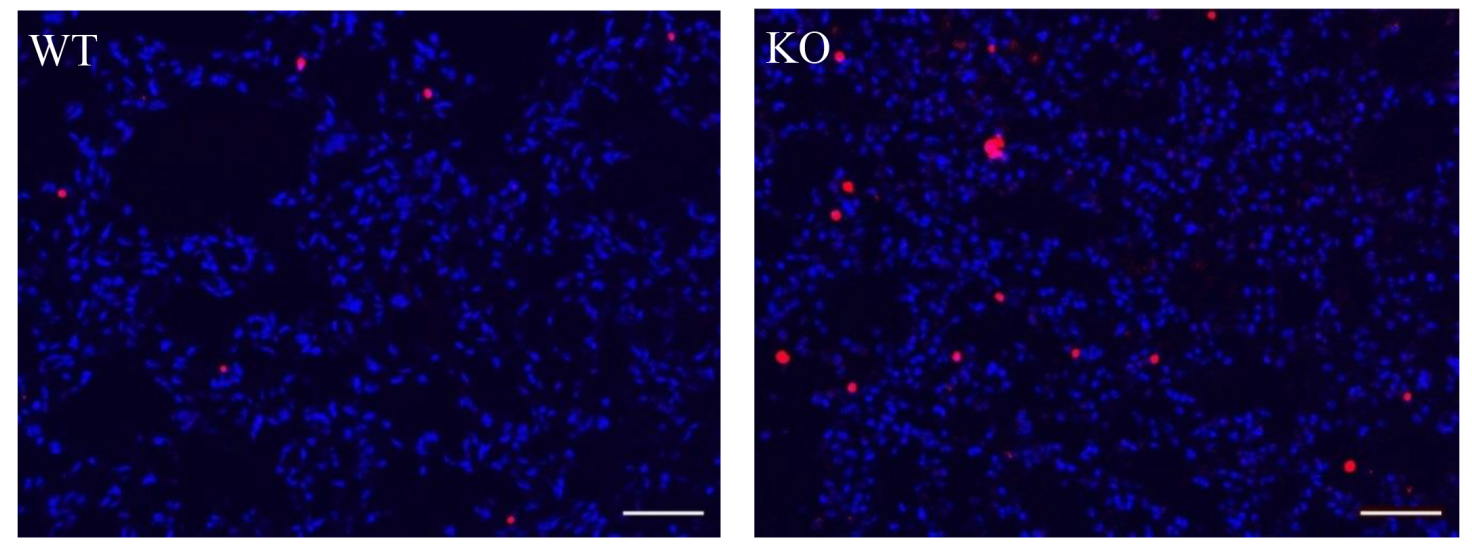

B

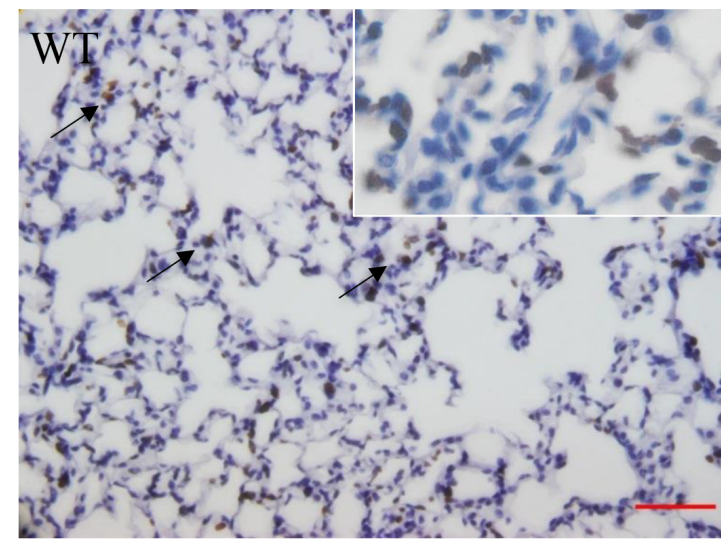

$\mathrm{C}$

TUNEL

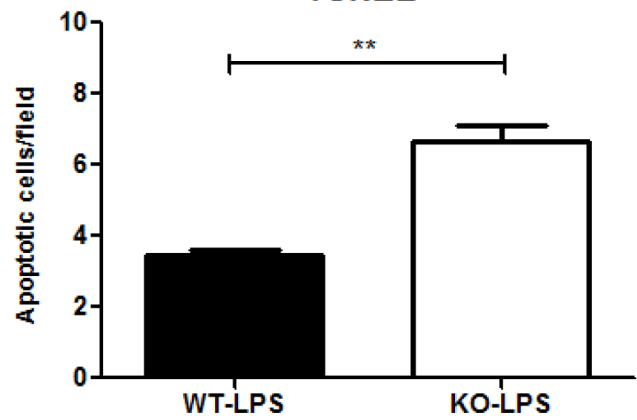

protein level in cultured human bronchial epithelial cells (unpublished data); LPS may inhibit XB130 expression and reduce the protective effects of XB130 in ALI. This may also explain the weak staining of phosphorylation of p $85 \alpha$ and Akt and GSK-3 $\beta$ on alveolar wall.

Interestingly, the numbers of $\mathrm{p}$-GSK-3 $\beta$ positively stained macrophages and neutrophils were significantly

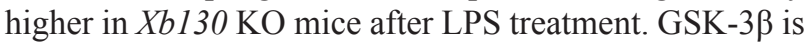
a serine threonine protein kinase, and a downstream target

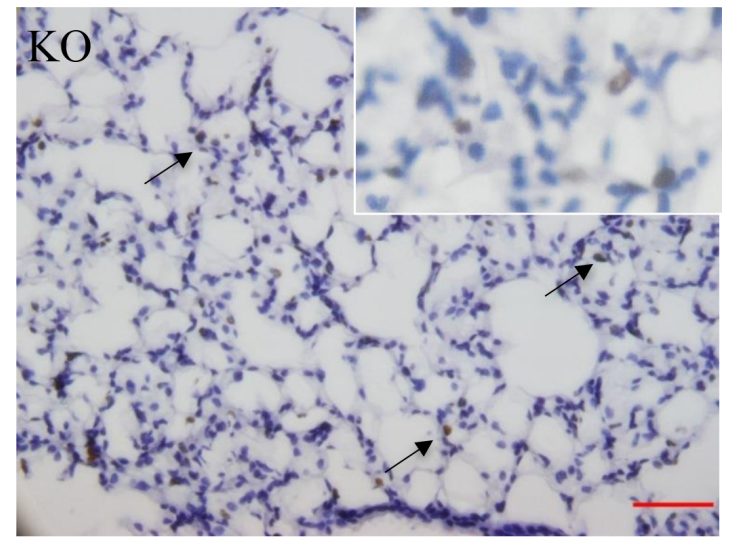

$\mathrm{D}$

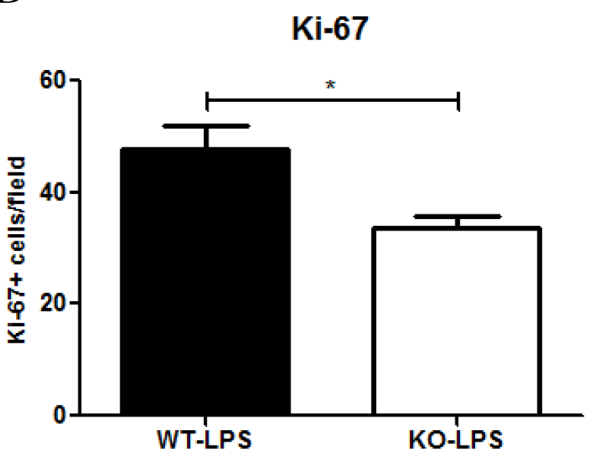

Figure 4: XB130 deficiency resulted in more apoptosis and less cell proliferation in LPS-induced lung injury. (A) The number of apoptotic cells (red) was significantly higher (A-C), and the number of Ki-67+ cells (brown) was significantly lower (B and D) in $X b 130 \mathrm{KO}$ mice compared to WT mice at Day 2 after LPS administration. Scale Bars $=50 \mu \mathrm{m} . * p<0.05$, ** $p<0.01$, WT $=$ Wild type, $\mathrm{KO}=X b 130$ knockout. 
A
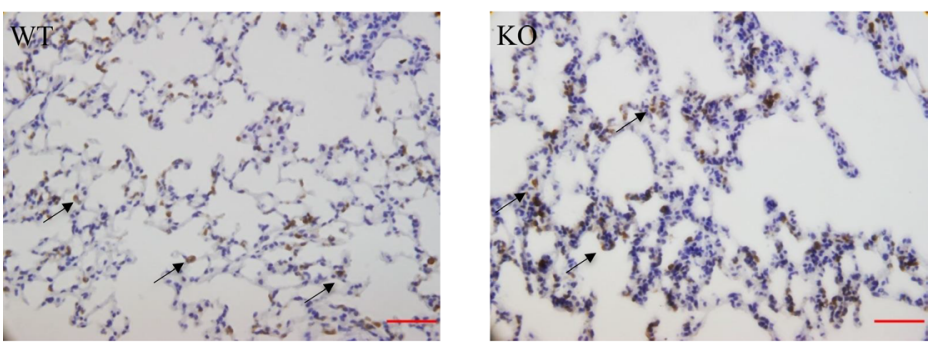

B
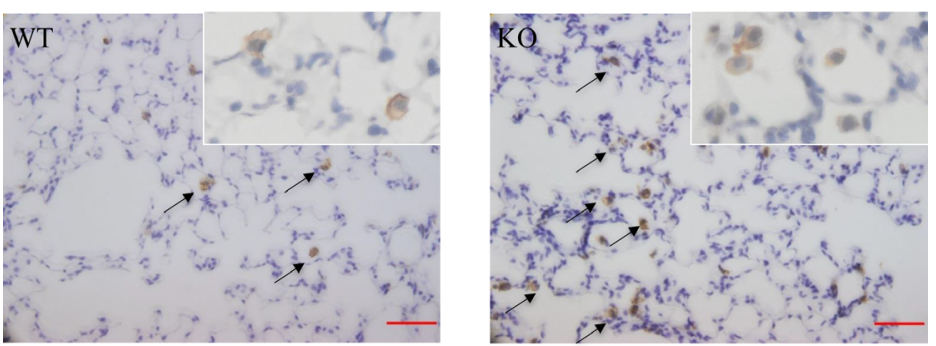

$\mathrm{C}$
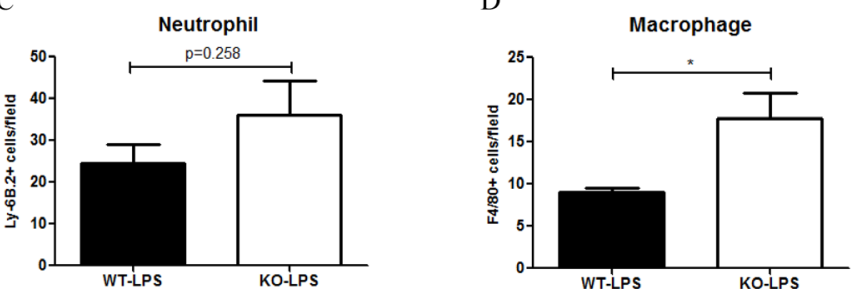

Figure 5: The number of neutrophils infiltrated into the alveoli at Day 2 after LPS treatment was not significantly different between WT mice and Xb130 KO mice (A-C). On the other hand, there was significantly higher number of macrophages infiltrated into the alveoli in $X b 130 \mathrm{KO}$ mice (B) (D). The neutrophils and macrophages were immunohistochemically stained with antibodies for Ly-6B2 and F4/80 antibodies, respectively. Scale Bars $=50 \mu \mathrm{m} .{ }^{*} p<0.05$, WT $=$ Wild type, KO $=X b 130$ knockout.

A
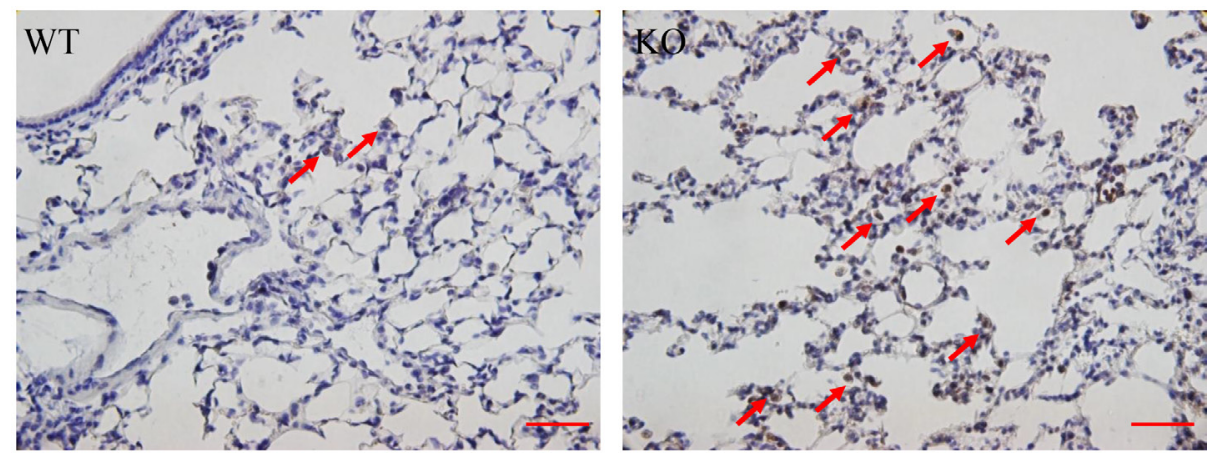

$\mathrm{B}$

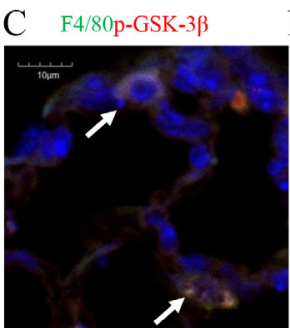

D Ly-6B.2/p-GSK-3ß

E Sftpc/p-GSK-3 $\beta$
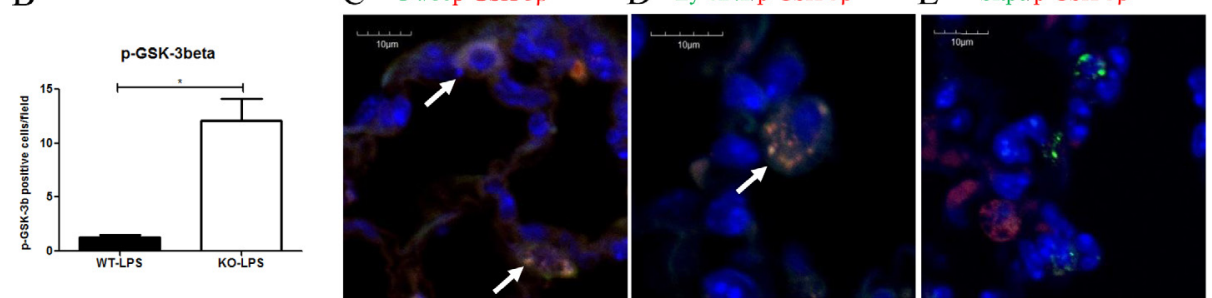

Figure 6: (A, B) Immunostaining for p-GSK-3 $\beta$ showed the number of p-GSK-3 $\beta+$ cells (brown) were significantly higher

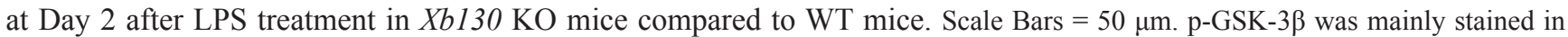
neutrophils and macrophages $(\mathbf{C}, \mathbf{D})$ but not in alveolar type II cells $(\mathbf{E}) .{ }^{*} p<0.05$, WT $=$ Wild type, $\mathrm{KO}=X b 130$ knockout. 
of PI3K/Akt pathway. Human monocytes stimulated with E. coli LPS demonstrated increased Ser 9 phosphorylation of GSK-3 $\beta$ [32]. The higher numbers of $\mathrm{p}-\mathrm{GSK}-3 \beta$ positive macrophages and neutrophils may be due to

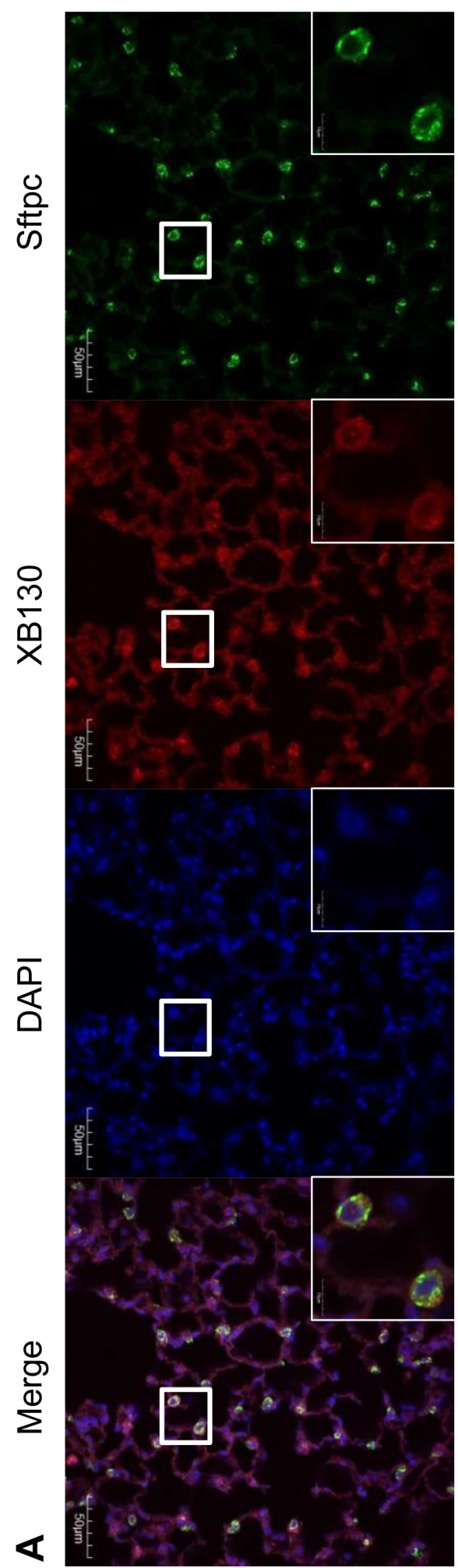

prolonged injury and delayed the repair of lung epithelial cells. The accumulation of macrophages in the lung tissue in $\mathrm{Xb130} \mathrm{KO}$ mice may contribute to the pathogenesis of ALI [33-35].

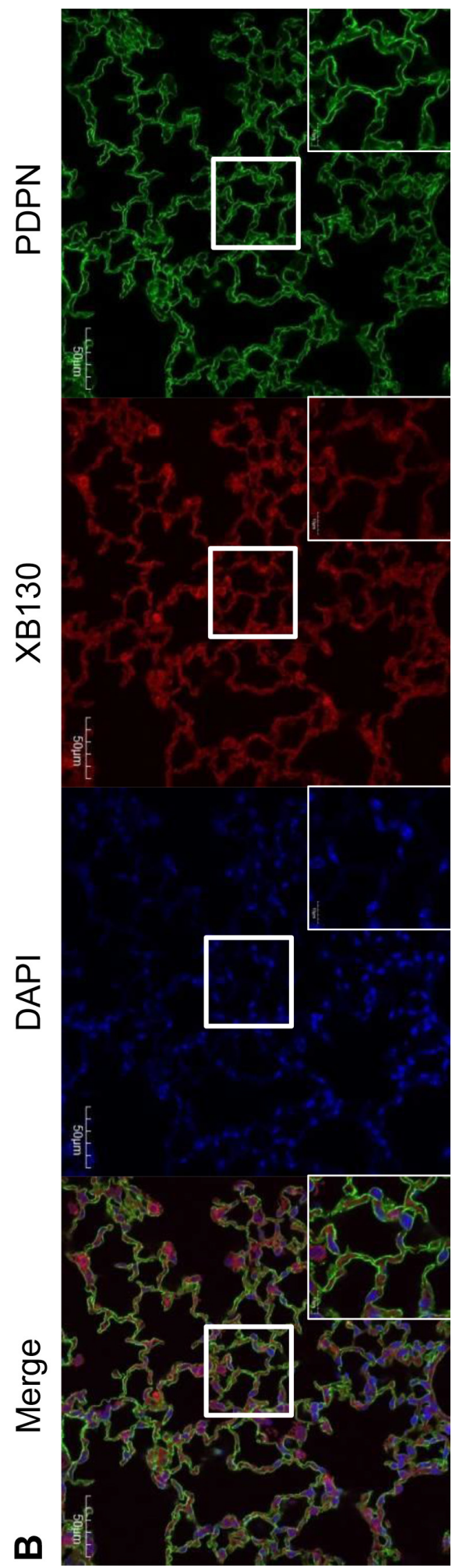

Figure 7: Immunofluorescence staining shows XB130 expression (XB130+: red) in alveolar type II cells (Sftpc+: green) (A) and type I cells (PDPN+: green) (B). PDPN = podoplanin, SFTPC = surfactant protein C. 
In conclusion, our results indicate that the presence of XB130 is protective to systemic septic response and related acute lung injury. Its deficiency reduces cell survival, promotes the infiltration of inflammatory cells into alveoli, increases pulmonary permeability, reduces cell proliferation, and slows down the repair process. XB130 expression can be inhibited by LPS challenge. Other ALI animal models should be used to further explore the roles of XB130. Moreover, the role of XB130 should be addressed directly in human ALI.

A

XB130 mRNA expression

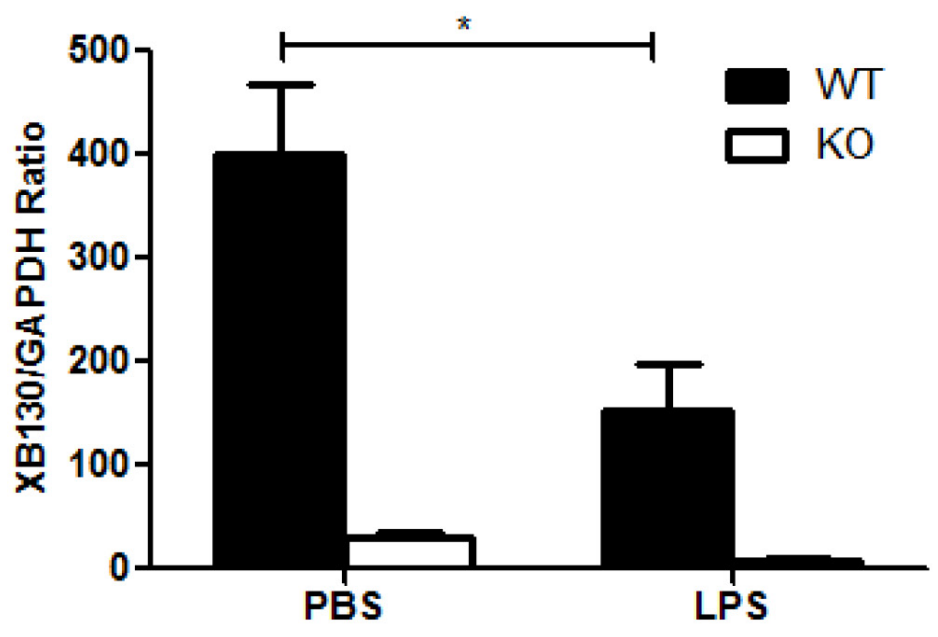

B
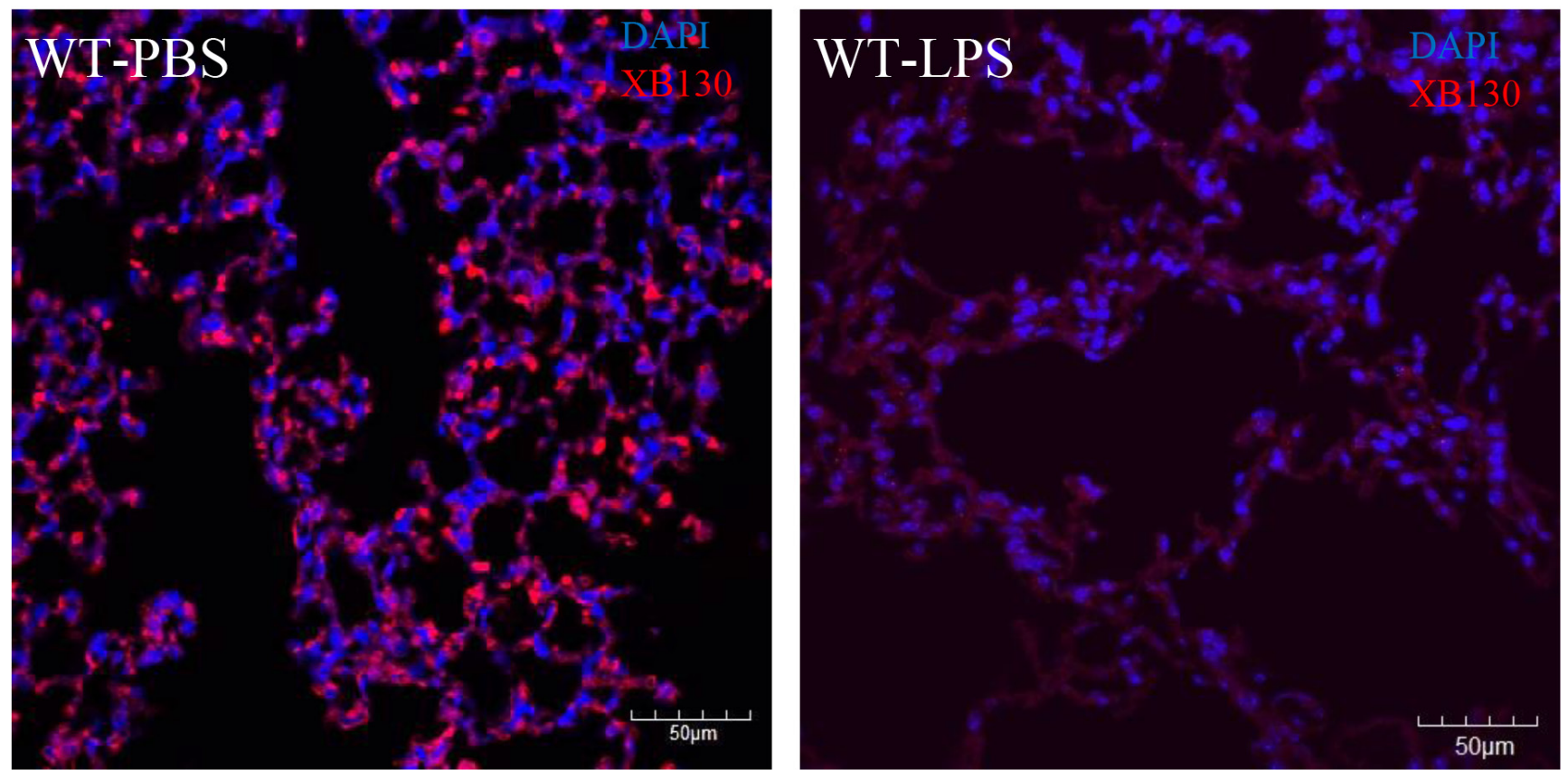

Figure 8: (A) In WT mice, Xb130 mRNA levels were significantly reduced in the lung tissue 2 days after LPS treatment. (B) Immunofluorescence studies shows that the intensity of XB130 (red) expression in alveolar epithelial cells was extremely weak after LPS administration. WT $=$ Wild type. 


\section{MATERIALS AND METHODS}

\section{Animal care}

The study protocol was approved by the Animal Use and Care Committee of the University Health Network. All animals were housed in a pathogen-free facility, with a 12-h light-dark cycle, and they were provided with free access to water and food, and received humane care in compliance with the Guide for the Care and Use of Experimental Animals formulated by the Canadian Council on Animal Care.

$\mathrm{Xb130} \mathrm{KO}$ mice were generated in collaboration with Dr. Tak W. Mak (University of Toronto) and maintained on a C57BL/6 genetic background. Xb130 KO mice showed a normal life span, and did not have obvious phenotypes in a series of physiological testing compared to wild-type (WT) littermates [16].

\section{LPS treatment and survival analysis}

Sepsis and ALI were induced in female $X b 130 \mathrm{KO}$ mice and their female WT littermates (20 weeks of age) by intraperitoneal injection of LPS $(25 \mathrm{mg} / \mathrm{kg}, E$. coli serotype 055:B5, Sigma-Aldrich, St. Louis, MO). Two groups of animals were used with 10 mice per group: 1) WT-LPS, 2) Xb130 KO-LPS. They were monitored for 7 days after LPS treatment for survival, body weight and composite disease score, based on the degree of ruffled fur, hunched appearance and lethargy [36]. Scores for each item were defined as 0 : not present, 1: mild, 2: severe. They were added with a maximum score of 6 .

\section{Assessment of acute lung injury and injury in other organs}

Four groups of animals were used with 5 mice per group: 1) WT-PBS, 2) WT-LPS, 3) Xb130 KO-PBS, 4) Xb130 KO-LPS. At Day 2 after administration, mice were sacrificed, and the lung, spleen, kidney and liver were harvested. The left lung and other tissues was fixed with $4 \%$ paraformaldehyde, and the upper lobe of the right lung was used for lung wet/dry (W/D) weight study, whereas the remaining lung tissue was snap-frozen and stored at $-80^{\circ} \mathrm{C}$. The lung wet/dry (W/D) weight ratio was calculated by dividing the lung tissue weight before and after drying it at $80^{\circ} \mathrm{C}$ for 48 hours. The lung and other tissues were embedded in paraffin and cut at $5 \mu \mathrm{m}$ thickness, and the sections were stained with hematoxylin and eosin (H \& E). Images were captured using Olympus BX51-FL (Olympus Co, Ltd). We randomly chose 5 fields $(\times 200)$ and assessed the lung injury with a modified score system [37]. Briefly, the alveolar edema/exudates, hemorrhage, and interstitial/alveolar cellular infiltration were scored on a scale of 1-3 (0: absent, 1: mild, 2: moderate, 3 : severe) with a maximum score of 9 [38-40].

\section{Immunohistochemistry (IHC) and} Immunofluorescence (IF) staining

The primary antibodies used were: rabbit antiXB130 (1:1,000, Abgent, San Diego, CA), rabbit antiKi67 (1:100, Lab Vision, Fremont, CA), rat anti-Ly-6B.2 (1:10,000, AbD Serotec, Raleigh, GC), rat anti-F4/80 (1:500, AbD Serotec), goat anti-podoplanin (PDPN) $(1: 50, R$ \& D Systems, Minneapolis, MN), rabbit antisurfactant protein C (SFTPC, for type II cells) $(1: 1,000$, Seven Hills Bioreagents, Cincinnati, $\mathrm{OH}$ ) and rabbit anti-phospho-GSK-3 $\beta$-Ser9 (1:500, Cell Signaling, Beverly, MA). After incubation with primary antibodies, sections were incubated with appropriate secondary antibodies. IHC was performed using a Vectastain ABC kit (Vector Laboratories, Burlington, Canada) with 3-3-diaminobenzidine as chromogen, and sections were counterstained with hematoxylin, and images were captured via Olympus BX51-FL. For IF, the secondary antibodies used were: donkey anti-goat Alexa Fluor ${ }^{\mathrm{R}}$ 488, donkey anti-rabbit Alexa Fluor ${ }^{\circledR} 555$ and goat antimouse Alexa Fluor ${ }^{\circledR} 555$ (1:200, Invitrogen, Burlington, Canada), and sections were mounted with Prolong Gold Antifade Mountant with DAPI ${ }^{\circledR}$ (Invitrogen). The slides were examined with an Olympus BX-51, and images were captured via QImaging colour camera (Olympus Co, Ltd). We randomly chose 5 fields $(\times 200)$ per slide for positive cell counting.

\section{TUNEL assay}

Cell Death was assessed by in situ terminal transferase dUTP nick end labelling (TUNEL) with In Situ Cell Death Detection Kit, TMR red (Roche, Penzberg, Germany). The slides were examined with an Axiovert 200M microscope (Zeiss, Oberkochen, Germany), and images were captured via CoolSnap HQ camera (Roper, Ottobrunn, Germany). TUNEL-positive cells were quantified from 10 randomly chosen fields per slide (× 400) using ImageJ (1.46r).

\section{Quantitative RT-PCR for XB130}

Total RNA was extracted using RNeasy kit (Qiagen, Duesseldorf, Germany). cDNA was synthesized from total RNA using MuLV reverse Transcriptase (Invitrogen). Quantitative RT-PCR was performed using SYBR Green I master PCR kit on Light Cycler480 (Roche Diagnostics). The Xb130 primer pairs used were 5'- TCAGCATCTCCAGAC-3' (forward) and 5'-GGCTGTTTCCTCTCT-3' (reverse). Each assay included a standard curve of six serial dilutions and notemplate negative control. All assays were performed in triplicate. The relative expression level of $X b 130$ was calculated after normalization with housekeeping gene GAPDH. 


\section{Cytokine/chemokine measurement}

For measurement of cytokine/chemokine, a separate set of animals was used with 5 mice per group. The serum was collected at 2, 6 and 48 hours after treatment, and bronchoalveolar lavage (BAL) fluid from the whole lung was collected at 48 hours after treatment as previously described [41]. Cytokines/chemokines levels in serum and cell-free BAL samples were measured using Milliplex MAP Mouse Cytokine/Chemokine Magnet Bead Panel (MCYTOMAG-70K-12, EMD Millipore, Billerica, MA).

\section{Statistical analysis}

All values were expressed as mean \pm standard error of the mean (SEM). Statistical analyses were performed by using Student's $t$-test or analysis of variance (ANOVA) with Bonferroni test as post-hoc analyses. Data were analyzed and plotted with GraphPad Prism 5.0 (GraphPad, La Jolla, CA). $P<0.05$ was considered to be statistically significant.

\section{ACKNOWLEDGMENTS}

We thank technical supports from Dr. Haibo Zhang and Dr. Claudia dos Santos and their lab members.

\section{GRANT SUPPORT}

This work was supported by the Canadian Institutes of Health Research (CIHR) operating grants MOP-13270, MOP-42546 and MOP-119514.

\section{CONFLICTS OF INTEREST}

No conflicts of interest, financial or otherwise are declared by the authors.

\section{REFERENCES}

1. Xu J, Bai XH, Lodyga M, Han B, Xiao H, Keshavjee S, Hu J, Zhang H, Yang BB, Liu M. XB130, a novel adaptor protein for signal transduction. J Biol Chem. 2007; 282:16401-16412.

2. Han B, Bai XH, Lodyga M, Xu J, Yang BB, Keshavjee $\mathrm{S}$, Post M, Liu M. Conversion of mechanical force into biochemical signaling. J Biol Chem. 2004; 279: 54793-54801.

3. Shiozaki A, Liu M. Roles of XB130, a novel adaptor protein, in cancer. J Clin Bioinforma. 2011; 1:10.

4. Bai XH, Cho HR, Moodley S, Liu M. XB130-A Novel Adaptor Protein: Gene, Function, and Roles in Tumorigenesis. Scientifica (Cairo). 2014; 2014:903014.

5. Lodyga M, Bai XH, Kapus A, Liu M. Adaptor protein $\mathrm{XB} 130$ is a Rac-controlled component of lamellipodia that regulates cell motility and invasion. J Cell Sci. 2010; 123:4156-4169.
6. Lodyga M, De Falco V, Bai XH, Kapus A, Melillo RM, Santoro M, Liu M. XB130, a tissue-specific adaptor protein that couples the RET/PTC oncogenic kinase to PI 3-kinase pathway. Oncogene. 2009; 28:937-949.

7. Shiozaki A, Shen-Tu G, Bai X, Iitaka D, De Falco V, Santoro M, Keshavjee S, Liu M. XB130 mediates cancer cell proliferation and survival through multiple signaling events downstream of Akt. PLoS One. 2012; 7:e43646.

8. Wu Q, Nadesalingam J, Moodley S, Bai X, Liu M. XB130 translocation to microfilamentous structures mediates NNK-induced migration of human bronchial epithelial cells. Oncotarget. 2015; 6:18050-18065. doi: 10.18632/oncotarget.3777.

9. Yamanaka D, Akama T, Fukushima T, Nedachi T, Kawasaki C, Chida K, Minami S, Suzuki K, Hakuno F, Takahashi S. Phosphatidylinositol 3-kinase-binding protein, PI3KAP/ $\mathrm{XB130}$, is required for cAMP-induced amplification of IGF mitogenic activity in FRTL-5 thyroid cells. Mol Endocrinol. 2012; 26:1043-1055.

10. Emaduddin M, Edelmann MJ, Kessler BM, Feller SM. Odin (ANKS1A) is a Src family kinase target in colorectal cancer cells. Cell Commun Signal. 2008; 6:7.

11. Zuo Q, Huang H, Shi M, Zhang F, Sun J, Bin J, Liao Y, Liao W. Multivariate analysis of several molecular markers and clinicopathological features in postoperative prognosis of hepatocellular carcinoma. Anat Rec (Hoboken). 2012; 295:423-431.

12. Shiozaki A, Kosuga T, Ichikawa D, Komatsu S, Fujiwara H, Okamoto K, Iitaka D, Nakashima S, Shimizu H, Ishimoto T, Kitagawa M, Nakou Y, Kishimoto M, et al. XB130 as an independent prognostic factor in human esophageal squamous cell carcinoma. Ann Surg Oncol. 2013; 20: 3140-3150.

13. Shi M, Huang W, Lin L, Zheng D, Zuo Q, Wang L, Wang N, Wu Y, Liao Y, Liao W. Silencing of XB130 is associated with both the prognosis and chemosensitivity of gastric cancer. PLoS One. 2012; 7:e41660.

14. Li J, Sun W, Wei H, Wang X, Li H, Yi Z. Expression of XB130 in human ductal breast cancer. Int J Clin Exp Pathol. 2015; 8:5300-5308.

15. Moodley S, Hui Bai X, Kapus A, Yang B, Liu M. XB130/ Tks5 scaffold protein interaction regulates Src-mediated cell proliferation and survival. Mol Biol Cell. 2015; 26:4492-4502.

16. Zhao J, Wang Y, Wakeham A, Hao Z, Toba H, Bai X, Keshavjee S, Mak TW, Liu M. XB130 deficiency affects tracheal epithelial differentiation during airway repair. PLoS One. 2014; 9:e108952.

17. Toba H, Wang Y, Bai X, Zamel R, Cho HR, Liu H, Lira A, Keshavjee S, Liu M. XB130 promotes bronchioalveolar stem cell and Club cell proliferation in airway epithelial repair and regeneration. Oncotarget. 2015; 6:30803-30817. doi: 10.18632/oncotarget.5062.

18. Rubenfeld GD, Caldwell E, Peabody E, Weaver J, Martin DP, Neff M, Stern EJ, Hudson LD. Incidence 
and outcomes of acute lung injury. N Engl J Med. 2005; 353:1685-1693.

19. Liu M. ARDS and knowledge translation. Intensive Care Med. 2008; 34:589-591.

20. Kawai T, Akira S. The role of pattern-recognition receptors in innate immunity: update on Toll-like receptors. Nat Immunol. 2010; 11:373-384.

21. Okutani D, Lodyga M, Han B, Liu M. Src protein tyrosine kinase family and acute inflammatory responses. Am J Physiol Lung Cell Mol Physiol. 2006; 291:L129-141.

22. Chen Y, Chang L, Li W, Rong Z, Liu W, Shan R, Pan R. Thioredoxin protects fetal type II epithelial cells from hyperoxia-induced injury. Pediatr Pulmonol. 2010; 45:1192-1200. doi: 10.18632/oncotarget.4253.

23. Hardy LA, Booth TA, Lau EK, Handel TM, Ali S, Kirby JA. Examination of MCP-1 (CCL2) partitioning and presentation during transendothelial leukocyte migration. Lab Invest. 2004; 84:81-90.

24. Knight PR, Davidson BA, Nader ND, Helinski JD, Marschke CJ, Russo TA, Hutson AD, Notter RH, Holm BA. Progressive, severe lung injury secondary to the interaction of insults in gastric aspiration. Exp Lung Res. 2004; 30:535-557.

25. Beck-Schimmer B, Schwendener R, Pasch T, Reyes L, Booy C, Schimmer RC. Alveolar macrophages regulate neutrophil recruitment in endotoxin-induced lung injury. Respir Res. 2005; 6:61.

26. Mukhopadhyay S, Hoidal JR, Mukherjee TK. Role of TNFalpha in pulmonary pathophysiology. Respir Res. 2006; $7: 125$.

27. Wu Q, Li R, Soromou LW, Chen N, Yuan X, Sun G, Li B, Feng H. p-Synephrine suppresses lipopolysaccharideinduced acute lung injury by inhibition of the NF-kappaB signaling pathway. Inflamm Res. 2014; 63:429-439.

28. Hiroshima Y, Hsu K, Tedla N, Chung YM, Chow S, Herbert C, Geczy CL. S100A8 induces IL-10 and protects against acute lung injury. J Immunol. 2014; 192:2800-2811.

29. Tang PS, Mura M, Seth R, Liu M. Acute lung injury and cell death: how many ways can cells die? Am J Physiol Lung Cell Mol Physiol. 2008; 294:L632-641.

30. Tomankova T, Kriegova E, Liu M. Chemokine receptors and their therapeutic opportunities in diseased lung: far beyond leukocyte trafficking. Am J Physiol Lung Cell Mol Physiol. 2015; 308:L603-618.
31. Shiozaki A, Lodyga M, Bai XH, Nadesalingam J, Oyaizu T, Winer D, Asa SL, Keshavjee S, Liu M. XB130, a novel adaptor protein, promotes thyroid tumor growth. Am J Pathol. 2011; 178:391-401. doi: 10.18632/oncotarget.1940.

32. Martin M, Rehani K, Jope RS, Michalek SM. Toll-like receptor-mediated cytokine production is differentially regulated by glycogen synthase kinase 3 . Nat Immunol. 2005; 6:777-784.

33. Lentsch $\mathrm{AB}$, Ward PA. Regulation of experimental lung inflammation. Respir Physiol. 2001; 128:17-22.

34. Serhan CN, Savill J. Resolution of inflammation: the beginning programs the end. Nat Immunol. 2005; 6: 1191-1197.

35. Strieter RM, Kunkel SL. Acute lung injury: the role of cytokines in the elicitation of neutrophils. J Investig Med. 1994; 42:640-651.

36. van Schaik SM, Abbas AK. Role of $\mathrm{T}$ cells in a murine model of Escherichia coli sepsis. Eur J Immunol. 2007; 37:3101-3110.

37. Han B, Haitsma JJ, Zhang Y, Bai X, Rubacha M, Keshavjee S, Zhang H, Liu M. Long pentraxin PTX3 deficiency worsens LPS-induced acute lung injury. Intensive Care Med. 2011; 37:334-342.

38. Han B, Ma X, Zhang J, Zhang Y, Bai X, Hwang DM, Keshavjee S, Levy GA, McGilvray I, Liu M. Protective effects of long pentraxin PTX3 on lung injury in a severe acute respiratory syndrome model in mice. Lab Invest. 2012; 92:1285-1296.

39. Gao W, Zhao J, Kim H, Xu S, Chen M, Bai X, Toba H, Cho HR, Zhang H, Keshavjeel S, Liu M. alpha1-Antitrypsin inhibits ischemia reperfusion-induced lung injury by reducing inflammatory response and cell death. J Heart Lung Transplant. 2014; 33:309-315.

40. Oyaizu T, Fung SY, Shiozaki A, Guan Z, Zhang Q, dos Santos CC, Han B, Mura M, Keshavjee S, Liu M. Src tyrosine kinase inhibition prevents pulmonary ischemiareperfusion-induced acute lung injury. Intensive Care Med. 2012; 38:894-905.

41. He X, Han B, Bai X, Zhang Y, Cypel M, Mura M, Keshavjee S, Liu M. PTX3 as a potential biomarker of acute lung injury: supporting evidence from animal experimentation. Intensive Care Med. 2010; 36:356-364. 